\title{
Reflexões sobre os empréstimos do tipo loanblend e direto na língua xerente akwén
}

\author{
Understanding the role of loanblend and calque \\ borrowings by Xerente Akwén from Portuguese
}

\author{
Silvia Lucia Bigonjal Braggio \\ Universidade Federal de Goiás
}

\begin{abstract}
In the last 15 years scholars from around the world have been showing the increasing number of minority languages death. Many of them have been creating sociolinguistic typologies that can handle the micro and macro-variables affecting them. At the level of language, borrowings have been considered as very threatening, mainly because they can be invisible to their speakers. Amongst the macro-variables, migration has been pointed out as critical, since in the cities the minority languages suffer a greater impact from the majority ones. My main goal in this article is to show and discuss how borrowings and migration are impacting the xerente akwén language in relationship to the mobility of the scenario the xerente akwén people are inserted in. The main results show that many more studies will be necessary to shed light to the present sociolinguistic situation.
\end{abstract}

Keywords

Languages into contact, Borrowings, Migration, Bilingualism 


\section{Resumo}

O cenário sociolinguístico das línguas minoritárias em contato com línguas majoritárias, geralmente as oficiais, tem apresentado sinais / indícios que apontam para um processo de desvitalização muitas vezes invisíveis para os falantes daquelas línguas. Com base nessa constatação, estudos tipológicos sociolinguísticos têm surgido mais recentemente a fim de desvelar as micro e macrovariáveis que possam estar afetando-as. Meu objetivo neste artigo é tratar dos empréstimos feitos pela língua xerente akwén da língua portuguesa, especialmente os do tipo loanblend e o direto em relação à situação de bilinguismo (microvariável) e do processo de migração (macrovariável) e seus efeitos na língua nativa. Os dados vêm sendo coletados desde os anos de 1990 e revisitados em vista da mudança de cenário nos últimos anos. Os resultados apontam novos temas de pesquisa que darão subsídios para uma compreensão mais profunda do atual estágio da língua.

\section{Palavras-chave}

Línguas em contato, Empréstimos, Migração, Bilinguismo 


\section{Considerações iniciais}

$\mathrm{O}$

cenário sociolinguístico de uma língua indígena minoritária em contato com uma língua majoritária, geralmente oficial, é sempre complexo, dadas as inúmeras variáveis que nele atuam. Consequentemente, não é tarefa fácil para o linguista descrever e analisar as relações intrínsecas entre a língua indígena e aquelas variáveis que têm mais peso na sua vitalização ou desvitalização, já que os fatores quem podem desvitalizar ou vitalizar uma língua são basicamente os mesmos. O estudo sociolinguístico de uma comunidade étnica indígena em um dado momento histórico, dependendo do foco de análise, pode observar processos que, já em sua origem, são indícios, pistas de uma situação que pode vir a se aprofundar à medida que a língua segue seu curso de desenvolvimento dentro de um determinado cenário. Isso não significa que os primeiros estudos sociolinguísticos em uma dada comunidade indígena sejam desnecessários, pelo contrário, são eles que levantam questões para futuras investigações. Em vista dessa afirmação, fica patente que um estudo sociolinguístico de base sólida deve necessariamente ser de longo prazo, já que, a não ser por motivos que desloquem a língua de um momento para o outro (morte de seus membros, proibição de usá-la), não só a língua apresenta variações e mudanças linguísticas propriamente ditas, o que é um processo natural de toda e qualquer língua, mas também aquelas variações podem ser oriundas de uma mudança no cenário que as acomoda e /ou das atitudes dos seus falantes.

O objetivo deste artigo é discutir o papel dos empréstimos do tipo loanblend e direto elaborados e usados pelos falantes de xerente akwén, da situação sociolinguística que lhes dá suporte e do que considero como o principal fator que levou à sua possibilidade: o contato intenso com a língua e falantes de português e, mais recentemente, a migração (veja BRAGGIO, 2008, 2009). As coletas de dados têm sido realizadas desde 1988, com observações in loco, questionários gravados, análises de materiais escritos, conversas informais, diários de campo, e todos os seus resultados estão devidamente documentados em artigos publicados e em relatórios técnico-científicos. 
A língua xerente akwén pertence à família Jê do Tronco Macro-Jê (RODRIGUES, 1986) e é falada por 3.100 indivíduos do mesmo nome distribuídos na Área Indígena Xerente e Área Indígena Funil, no estado do Tocantins, dentro da chamada Amazônia Legal. Trata-se de um povo que tem tido contato com a sociedade não indígena há mais de 100 anos. É uma língua basicamente aglutinante e SOV. Também pode se classificar seu povo, do ponto de vista sociolinguístico, como bilíngue, já que a maioria de seus membros domina e usa a língua nativa e a língua portuguesa (BRAGGIO, 1992, 1995, 1997). É necessário também frisar que o contato com a cidade de Tocantínia, a mais próxima das áreas, é intenso, inclusive com vários alunos xerente akwén estudando em escolas dessa cidade. Por volta de $10 \%$ da população total ali vivem. Todos esses pontos são tratados a seguir.

Em 1989 fiz meu primeiro contato com o povo indígena xerente akwén a fim de fazer um levantamento da situação sociolinguística para fornecer subsídios a um projeto de educação para os professores indígenas do estado do Tocantins (1992). Esse estudo foi feito na aldeia Porteira, então a mais populosa das seis aldeias existentes. De base funcionalista, foi aplicado um questionário a 20\% da população com 32 questões, distribuídas de acordo com faixa etária e sexo, verificando: (i) conhecimento das línguas, (ii) uso das línguas nos diferentes domínios sociais e (iii) atitudes dos falantes com relação a elas (a língua nativa e a portuguesa.). Em vista dos meus objetivos com relação a este artigo, destacarei três aspectos dos resultados obtidos: 98\% da população entrevistada afirmavam falar, ou falar um pouco, a língua portuguesa; a língua adquirida como L1 (primeira língua) era a nativa e a língua preferida para a escolarização era somente a portuguesa, ou ambas as línguas. Uma porcentagem mínima de 7\% (mulheres) e de 17\% (homens) afirmava preferir a língua nativa. Com base nesses resultados e em outros apresentados nas demais questões, pude concluir que: (1) o povo xerente akwén transmitia a sua língua de geração para geração; (2) era bilíngue e (3) preferia a língua portuguesa como a língua da escolarização. Embora limitados, esses resultados já me davam uma pista do cenário que viria a seguir. Em 1991 teve início o Curso de Formação para os Professores Indígenas do Estado do Tocantins, do qual fui uma das elaboradoras, coordenadoras e professora. Nele permaneci até 2000, trabalhando mais junto aos Xerente, o que me levou a conhecer sua língua, história e cultura com mais profundidade e, em consequência, as transformações que foram se operando 
nesse período. Foi durante o curso que percebi que as aldeias estavam se multiplicando como cogumelos. Das seis existentes em 1989, há hoje 56 aldeias. Os conflitos latentes entre os diferentes clãs (BRAGGIO, 1999) estavam se acirrando com a construção de uma estrada de rodagem, principalmente para ônibus, que passaria pelas áreas. Alguns a favor, outros contra. Foi construída. Hoje os ônibus são o principal meio de transporte dos Xerente para Tocantínia, o que fazem regularmente, e para outras cidades da região. Logo em seguida veio a construção de uma barragem inundando parte da área xerente e a criação da PROCAMBIX (Programa de Compensação Ambiental Indígena Xerente). As aulas, antes em um ritmo normal para uma sala de aula, começavam sempre com um debate entre eles sobre os problemas que afligiam o povo xerente. Comecei a ouvir que os Xerente Akwén falavam duas línguas: a dos mais velhos e a dos mais jovens. Esse fato não me havia passado despercebido e as diferentes escritas da língua deixavam marcas inconfundíveis de que havia duas variedades, exatamente a dos mais velhos e a dos mais jovens. Como antes do curso pouquíssimas pessoas escrevessem na língua (ou eram autorizadas a escrever na língua, além do que havia nas cartilhas), o fato de muitas pessoas poderem escrever na própria língua trouxe à tona um conflito outrora não existente: em que língua (variedade) escrever? O que podemos escrever sem a autorização da comunidade? Isso ficou claro na época das primeiras publicações dos materiais escritos por eles durante o curso. Enquanto não houve problemas com as outras etnias presentes no curso (Karajá, Javaé, Krahó, Apinajé), ou se havia, eles mesmos resolviam, os Xerente levavam os escritos para as aldeias a fim de discutir se podiam ser ou não publicados e em que variedade. Note-se que não se tratava da escrita de mitos de origem e outros. Estávamos tentando começar a sistematizar o conhecimento de cada etnia. Portanto, eram descrições dos peixes, animais e plantas existentes nas áreas, dos objetos usados no dia a dia, das receitas de comida, chás, etc. Decidi, então, explorar mais a fundo a situação sociolinguística e aspectos da linguagem oral e escrita em um projeto individual.

Durante o período de dois anos do projeto trabalhei com a professora xerente Edite Smikidi que atuava na Aldeia Salto. Decorrente desse projeto foram coletados mais de 200 textos escritos por crianças em fase de alfabetização que foram preciosos para a análise da língua portuguesa e da nativa. A conclusão mais contundente a que cheguei no projeto foi a de que a instauração da língua escrita entre os Xerente trazia conflitos, mas que foi através dela que eles, em escrita 
coletiva em língua portuguesa, passaram a fazer documentos que chegaram, inclusive, a ser levados a Brasília, mostrando uma atitude de resistência. Foi no entremeio desse período que passei a notar o aumento do uso dos empréstimos da língua portuguesa de vários tipos e de codeswitchings constantes entre os falantes, o que indicava um contato muito mais intenso dos Xerente Akwén com os não indígenas. Foi a partir dos indícios iniciais e das transformações ocorrendo no período que levantei questões que julguei pertinentes para posteriores estudos:

Se a língua xerente akwén está sendo passada de geração em geração, quais os aspectos da língua que levam os mais velhos e os mais jovens a afirmarem que não se entendem?

Que fatores extralinguísticos estão atuando na atual configuração da língua xerente akwén?

O contato mais intenso com a língua portuguesa está levando à desvitalização da língua xerente akwén?

Essas questões deram origem aos projetos que venho desenvolvendo desde 2003 e que trato a seguir.

\section{A tipologia sociolinguística: os empréstimos do tipo loanblend, os diretos e a migração}

Em cenário tão complexo e tão pleno de tópicos a serem investigados, optei por me dedicar, como pesquisadora, totalmente à língua xerente akwén, não de maneira solitária, mas agregando outros pesquisadores: professores de outra instituição, alunos de graduação e pós-graduação, mestrado e doutorado (SOUSA FILHO, 2007; VIEIRA, 2005; MESQUITA, 2009; SIQUEIRA, 2009; ANDRADE, 2009; SOUZA, 2008, entre outros trabalhos dos mesmos autores e de Daniele Marcelle Grannier que possui trabalhos apresentados em encontros e congressos, mas ainda não publicados). As várias pesquisas e estudos têm dado suporte uns aos outros e isso tem se mostrado bastante significativo para um estudo mais verticalizado da língua xerente akwén. Em meu campo de estudo, já ciente da perda das línguas minoritárias no mundo(WURM, 1991; FISHMAN, 2000) e das tipologias sociolinguísticas que estavam sendo elaboradas para dar conta desse fenômeno, optei por trabalhar com as de Edwards (1992 ), e de Grenoble \& Whaley (1998), pois elas enfocam a língua nas suas íntimas conexões com as macrovariáveis que a afetam, positiva ou negativamente. 
Neste artigo trato especificamente dos empréstimos do tipo loanblend, diretos e da migração (em outros trabalhos já publicados: (i) trato dos empréstimos propriamente ditos ocorrendo na língua; (ii) faço uma revisão da fonética e fonologia dos dados lexicais de Martius (1865, em Maybury-Lewis, 1966 ) e Maybury-Lewis (1966 ), comparando-os aos dados atuais, apontando os processos fonológicos que ocorreram e ocorrem na língua e que podem ser uma das causas do não entendimento pleno entre as diferentes gerações e (iii) aponto o papel dos empréstimos na sua relação com a dispersão areal, migração e escolarização em uma possível desvitalização do léxico da língua xerente akwén) entre outros artigos mais gerais.

\section{Os empréstimos e a situação de bilinguismo}

Em Xerente Akwén há quatro tipos de empréstimos: os de criação, os que passam pelo filtro da língua, os loanblends e os diretos. Através deles pode-se identificar uma determinada situação sociolinguística em um continuum com diferentes graus de bilinguismo individual e social. Em uma análise anterior dividimos a população xerente akwén em três faixas etárias: os mais velhos, a partir de 50 anos (+velhos), os mais ou menos jovens, de 20 a 49 anos (+-jovens) e os mais jovens, de 12 a 19 anos (+jovens).

\section{Empréstimos por criação e bilinguismo incipiente}

Os empréstimos por criação mostram uma situação inicial (incipient bilingualism) de bilinguismo e a língua nativa bastante vitalizada já que ela é a base de referência para a entrada dos novos itens lexicais. Eles são criados a partir da própria língua e se manifestam principalmente no léxico nominal (atente-se para os processos fonológicos entre as gerações) e no uso dos +velhos e +-jovens: 


\begin{tabular}{|c|c|c|}
\hline \multirow[t]{2}{*}{ Português } & \multicolumn{2}{|c|}{ XerenteAkwén/Português } \\
\hline & (+velhos) & (+-jovens) \\
\hline papel & $\begin{array}{c}\text { haisuka } \\
\text { (folha para escrever) }\end{array}$ & hesuka \\
\hline lápis & $\begin{array}{c}\text { ikuikreze } \\
\text { (coisa com que a gente escreve) }\end{array}$ & ikuikreze \\
\hline rádio & $\begin{array}{c}\text { târãmrẽmẽ } \\
\text { (ferro que fala) }\end{array}$ & târãmrẽmẽ \\
\hline escola & $\begin{array}{c}\text { rowahtze } \\
\text { (lugar de ensinar) }\end{array}$ & rowahtze \\
\hline bicicleta & $\begin{array}{c}\text { sumzari } \\
\text { (feito o cavalo) }\end{array}$ & sumzari \\
\hline melancia & wde krukrãize & wde krukẽze \\
\hline laranja & wde krãikuze & wde krẽkuze \\
\hline enxada & ktpó & ktpó \\
\hline
\end{tabular}

Note-se que não incluímos os +jovens nessa amostra, pois os exemplos mais atuais mostram que os empréstimos diretos são os mais usados (MESQUITA, 2009). Outra observação é que os termos para rádio, bicicleta, enxada e muitos outros não apontados nessa amostra estão deixando de ser usados.

\section{Empréstimos que passam pelo filtro da língua e bilinguismo avançado}

Os empréstimos que passam pelo filtro da língua mostram uma situação de maior contato e um grau de bilinguismo individual e social um pouco mais avançado, mas a língua nativa ainda é a base para a entrada dos novos itens, mais “aportuguesados” como apontados nos exemplos anteriores e usados pelos +jovens e +jovens: 


$\begin{array}{cc}\text { Português } & \begin{array}{c}\text { Xerente Akwén } \\ \text { (+-jovens) e (+jovens) }\end{array} \\ \text { lápis } & \text { rapi(s) } \\ \text { rádio } & \text { had(i) } \\ \text { escola } & \text { scora(a) } \\ \text { trator } & \text { tratô } \\ \text { bicicleta } & \text { bicicret } \\ \text { melancia } & \text { mrãsi } \\ \text { laranja } & \text { rarã } \\ \text { enxada } & \text { inxad }\end{array}$

\section{Empréstimos do tipo loanblend e bilinguismo alto}

Os empréstimos do tipo loanblend somente ocorrem quando há um alto grau de bilinguismo individual e social (high bilingualism), de proficiência do falante no uso das duas línguas em contato, pois o seu cérebro/mente está operando com as duas línguas simultaneamente, e de bilinguismo avançado na sociedade, já que os empréstimos são entendidos pela maioria dos falantes, com exceção dos +velhos que muitas vezes não têm acesso ao léxico dos +jovens, que os elaboram, e não aceitam o que chamam de "mistura de línguas”. As duas línguas estão em concorrência. A situação sociolinguística em termos de atitudes linguísticas é de diglossia conflituosa.

$\begin{array}{cc}\text { Português } & \begin{array}{c}\text { Xerente Akwén } \\ \text { (+-jovens) e (+jovens) } \\ \text { mãe } \\ \text { mãe/ mãerê } \\ \mathrm{N} \text { qualificador } \\ \text { mãezinha }\end{array} \\ \text { pai } & \text { pai/ pairê } \\ \mathrm{N} \text { qualificador } \\ \text { paizinho } \\ \text { dinheiro } \\ \\ \text { ktaprezuzi } \\ \mathrm{N} \text { qualificador } \\ \text { classificador preço-zinho } \\ \text { dinheirinho }\end{array}$




\begin{tabular}{|c|c|}
\hline telhado & $\begin{array}{l}\text { krikusubiz3 } \\
\text { V=subir } \\
\text { casa para cima subir nominalizador } \\
\text { telhado }\end{array}$ \\
\hline açougue & $\begin{array}{l}\text { inĩvẽdez3 } \\
\text { V=vender } \\
\text { carne vender nominalizador } \\
\text { açougue }\end{array}$ \\
\hline pão & $\begin{array}{c}\text { pãukr3 } \\
\text { N=pão } \\
\text { pão- comer } \\
\text { padaria }\end{array}$ \\
\hline xarope & $\begin{array}{l}\text { dakakuramõz3 } \\
\qquad \begin{array}{l}\mathrm{V}=\text { curar } \\
\text { tosse curar para nominalizador }\end{array}\end{array}$ \\
\hline cobert(a)/or & $\begin{array}{l}\text { xarope } \\
\text { sikubisibizz } \\
\text { V=cobrir-se } \\
\text { reflexivo cobrir-se com nominalizador }\end{array}$ \\
\hline
\end{tabular}

É de significativa importância observar a complexidade de um empréstimo desse tipo em línguas tipologicamente diferentes. Só quem domina as duas línguas é capaz de fazê-lo. Para o linguista fica a questão de quais são os critérios para a sua elaboração. Portanto, um ponto ainda a ser pesquisado.

\section{Os empréstimos diretos e o avanço da língua portuguesa}

Os empréstimos do tipo direto ocorrem quando o falante adquiriu a língua na infância, simultaneamente ou sucessivamente, portanto com proficiência nas duas línguas. Como a sociedade já é altamente bilíngue, são compreendidos pela maioria, mas não aceitos pela geração +velha. O léxico dos +jovens distanciase cada vez mais do dos +velhos na medida em que o contato daqueles com os não indígenas aumenta. A situação sociolinguística, obviamente, é bastante conflituosa. A língua portuguesa avança. Marcas do Português regional estão presentes. 


$\begin{array}{cc}\text { Português } & \text { Xerente } \\ \text { café } & \text { café } \\ \text { cavalo } & \text { cavalu } \\ \text { banco } & \text { bancu } \\ \text { xarope } & \text { xaropi } \\ \text { dinheiro } & \text { dinheru } \\ \text { cheque } & \text { chequi } \\ \text { açúcar } & \text { açúca } \\ \text { tênis } & \text { tênis } \\ \text { calcinha } & \text { calcinha } \\ \text { calça } & \text { calça } \\ \text { terno } & \text { ternu } \\ \text { panela } & \text { panela }\end{array}$

Note-se que fonemas do Português estão sendo utilizados sem influência da língua nativa.

\section{Reflexões finais}

Este artigo, ao complementar estudos anteriores e em andamento, constata, através dos tipos de empréstimos (com as variações) e da situação sociolinguística que os fundamenta (que não havia sido apresentada em outros artigos), o conflito mais acentuado entre as gerações, tornando mais visíveis as diferentes variedades dos +velhos e a dos +jovens, quando da instauração da escrita. É importante observar nesta reflexão final que a maior parte dos exemplos por criação está deixando de ser usada pela geração +jovem e muitos são estigmatizados como "velhos, fora de uso". Os do tipo loanblend não só são criados pelos + jovens, como usados e passados para as crianças em processo de aquisição da língua xerente akwén. Em pesquisa quantitativa, Mesquita (2009) aponta que são os +jovens os que mais usam os empréstimos diretos, principalmente os que moram na cidade de Tocantínia, mas que vão regularmente às suas aldeias de origem. Em vista dos resultados, parece-me implausível não apontar o contato cada vez mais intenso dos Xerente Akwén em seu processo acelerado de migração para a cidade de Tocantínia como um fator que pode, sim, desvitalizar a língua xerente akwén. É na cidade que a língua nativa está deslocada, fragilizada. Fora de seu nicho fica aberta à entrada da língua portuguesa com a avalanche de novos termos oriundos da terminologia escolar, da tecnologia e mesmo das coisas mais simples do cotidiano, como a televisão, 
o rádio, o supermercado e seus itens, as negociações, as leis da cidade, as formas de nela se movimentar sem ser considerado "estrangeiro", enfim, mover-se em uma cultura completamente diferente da sua em que "falar bem” o Português é, sem dúvida, uma forma de se sentir menos estigmatizado. Obviamente, o processo de migração não tem sido ao acaso. Como se verificou, ao longo desses anos, o cenário foi mudando rapidamente sem dar tempo aos Xerente Akwén de uma tomada de decisão coletiva e não cindida como está acontecendo, em favor deles mesmos. A estrada, a barragem, a inundação de parte de suas terras e os projetos compensatórios da PROCAMBIX de granja e plantação mecanizada, que poluem seus rios e impactam no ecossistema, não seriam fatores negativos para esse povo? Mais, quando noto a proliferação das aldeias como cogumelos e a migração, não posso deixar de apontar uma desconstrução do sistema de parentesco, de patrilocal para patriarcal, tanto na aldeia (dispersão areal) quanto na cidade. No sistema patrilocal, o homem vai morar com a família da mulher e deve prestar serviços ao sogro, portanto o “chefe” da casa é o pai da mulher. Em vista da mudança de cenário, ficam as seguintes questões: desvelar as atitudes e não apenas diagnosticar as razões que levam os Xerente Akwén a migrar e que outros aspectos da língua estão sendo afetados. O que tem chamado minha atenção ultimamente, obviamente, em vista da mudança de cenário é o da posse: os termos inalienáveis / alienáveis ou o que é considerado como posse e o que não pode ser de posse individual. Os termos de parentesco e as partes do corpo nunca aparecem sem um possuidor marcado pelo pronome de posse. Vimos que estão entrando na língua termos como “pai” (pai), “mãe” (mãe) em substituição ao meu pai, minha mãe, na língua nativa, sem o pronome de posse. Mesmo com os animais, quando se referem a algo que julgam da posse daqueles, a língua apresenta a seguinte forma: "sika-kre” (galinha-ovo)>(ovo da galinha). O item lexical ovo não aparece isolado sem o seu possuidor. Portanto, o ovo é propriedade da galinha e não de quem possui a galinha e o ovo. Neste caso, usase: Smikidi sika-kre (O ovo da galinha da Smikidi). Se, na cidade, a pessoa "compra" o ovo e o leva para "sua" casa, haveria a possibilidade de um Xerente Akwén usar “meu ovo”, “minha casa”, etc. usando os pronomes possessivos? Como ficam os termos de parentesco? A relação de parentesco e as funções a ela concernentes, como a do marido da mulher / genro, parece-me, fica impossível de ser a mesma daquela da aldeia. Na cidade, o "chefe” é o marido. Haveria nos dois casos uma dissolução do sistema de posse e do de parentesco? Enfim, neste processo de contato cada vez mais intenso com a sociedade não 
indígena, existe a possibilidade de que a língua, que traz as marcas culturais, seja afetada em outras áreas? Além do mais, é de importância fundamental levantar os critérios dos falantes, como afirmei anteriormente, para a elaboração dos loanblends. Cenário, portanto, a ser investigado, antes que as mudanças ocorram debilitando a língua, e cujas investigações possam contribuir para políticas linguísticas coletivas do povo xerente akwén.

\section{Nota}

${ }^{1}$ Este artigo pertence ao projeto LIBA: Línguas Indígenas Brasileiras Ameaçadas: documentação (descrição e análise) e tipologias sociolinguísticas (projeto guardachuva). Meu subprojeto atual, Bolsa PQ, 1D, projeto 3047/2006-7 é financiado pelo CNPq.

\section{Referências Bibliográficas}

ANDRADE, Paulo H. G. de (2007-2009) A varidade étnica do Português Xerente: aportes sociolinguísticos. Dissertação (Mestrado) - UFG. Em andamento.

BRAGGIO, Silvia L. B. Situação sociolinguística dos povos indígenas do estado de Goiás e Tocantins. Revista do Museu Antropológico. Goiânia-GO, UFG, n. 1, v. 1, p. 1-62, 1992.

BRAGGIO, Silvia L. B. The sociolinguistic situation of native peoples of Central Brasil: from trilingualism to language loss. LETRAS. Campinas: PUCCAMP, v.16, n.1 e 2, p. 31-54, 1995.

BRAGGIO, Silvia L. B. Aquisição e uso de duas línguas: variedades, mudança de código e empréstimo. Revista da Abralin. Maceió-AL, UFAL, v. 1, n. 20, p. 139172, 1997.

BRAGGIO, Silvia L. B. A instauração de escrita entre os Xerente: conflitos e resistências. Revista do Museu Antropológico. Goiânia-GO, UFG, v. 3/4, p. 19-52, 1999.

BRAGGIO, Silvia L. B. Línguas indígenas ameaçadas: documentação, tipologias sociolinguísticas e educação escolar. In: SILVA, Denise E. G. da (Org.). Língua gramática e discurso. Editora Cânone/GELCO, 2006.

BRAGGIO, Silvia L. B. Revisitando a fonética/fonologia da língua xerente akwe : uma visão comparativa dos dados de Martius (1865) a Maybury-Lewis (1966) com os de Braggio (2004). Signótica. Goiânia: Ed.da UFG, n. 16, p. 251-274, 2006. 
BRAGGIO, Silvia L.B. Indícios sobre a situação do léxico na língua xerente akwén: uma reflexão sobre os empréstimos e sua relação com a dispersão areal, a migração e a escolarização. Revista UniverSOS. Universidade de València: Espanha, n. 5, p. 193-216, 2008.

BRAGGIO, Silvia L. B. Tipologias sociolinguísticas: as macrovariáveis e seu papel na desvitalização das línguas: a língua xerente akwén. In: BRAGGIO, S. L. B.; SOUSA FILHO, S. M. de (Org.). Línguas e Culturas Macro-Jê. CAPES/UFG: Gráfica Vieira, 2009. p. 79-100.

EDWARDS, John. Sociopolitical aspects of language maintenance and loss: towards a typology of minority language situations. In: FASE, Willem et al.(Ed.). Maintenance and loss of minority languages. Amsterdam: Benjamins, 1992. p. 37-54.

FISHMAN, Joshua (Ed.). Can threatened languages be saved. Clevedon, Multilingual Matters, 2000.

GRENOBLE, Lenore; WHALEY, Lindsay J. Toward a typology of language endangerment. In: GRENOBLE, Lenore A.; WHALEY, Lindsay J. (Ed.). Endangered languages. Cambridge: Cambridge University Press, 1998. p. 22-54.

MAYBURY-LEWIS, David. "On Martius" distinction between Shavante and Sherente. Revista do Museu Paulista. São Paulo, USP, v. XVI, Nova Série, p. 16-43, 1966.

MESQUITA, Rodrigo. Os empréstimos linguísticos do Português pelo Xerente Akwén. 2009. Dissertação (Mestrado) - UFG, Goiânia, 2009.

RODRIGUES, Aryon D. Línguas Brasileiras. Para o conhecimento das línguas indígenas. São Paulo: Loyola, 1986.

SIQUEIRA, Kenia M. (2007-2009). Descrição e análise dos classificadores nominais em xerente akwén. Tese (Doutorado). Em andamento.

SOUSA FILHO, Sinval M. de. Aspectos morfossintáticos da língua akwén xerente. 2007. Tese (Doutorado) - UFG, Goiânia, 2007.

SOUZA, Shelton. Descrição fonético-fonológica da língua akwén xerente. 2008. Dissertação (Mestrado) - UnB, Brasília, 2008.

VIEIRA, Raquel P. O papel da língua nativa na aquisição da segunda língua escrita na escola indígena xerente, Waikarnãse. 2005. Dissertação (Mestrado) UFG, Goiânia, 2005.

WURM, Steven. Language death and disappearance: causes and circumstances. In: ROBINS, Robert; UHLENBECK, Eugenius (Ed.). Endangered languages. Oxford: Berg, 1991. 